\title{
New immunofluorescent blood test for gluten sensitivity
}

\author{
D J UNSWORTH, P D MANUEL, J A WALKER-SMITH, C A CAMPBELL, G D JOHNSON, \\ AND E J HOLBOROW
}

MRC Immunology Group, Bone and Joint Research Unit, London Hospital Medical College

SUMMARY A new test for the detection of antibodies to gliadin in the sera of children who are gluten sensitive is described. This test is based on the observation that wheat protein binds selectively to connective tissue fibres in cryostat sections of mammalian tissues. Sera containing antibodies to gliadin give a reticulin pattern of staining on sections pretreated with wheat gliadin if tested by indirect immunofluorescence. Antibodies to gliadin were detected in this manner in sera from all of 32 children with coeliac disease, in 16 of whom a provisional diagnosis had been given and in 16 an established diagnosis confirmed by gluten challenge. The incidence of reticulin antibodies detected on untreated sections (in the absence of gliadin) was only $28 \%$. Gliadin antibodies were also present in sera from $15 \%$ of 152 children with gastroenterological disorders other than coeliac disease, but most of these non-positive results for coeliac disease were in patients with transient gluten intolerance, cows' milk-sensitive enteropathy, or Crohn's disease. This new test, although not specific for coeliac disease, promises to be of value as an indicator of gluten sensitivity, and when negative excludes $क$ diagnosis of coeliac disease. It may also be useful in monitoring diet, and in determining wher rebiopsy after gluten challenge is appropriate.

According to the criteria of the European Society for Paediatric Gastroenterology and Nutrition (ESPGAN), ${ }^{1}$ a diagnosis of coeliac disease is dependent on examination of 3 small-intestinal biopsies taken before and during adherence to a strict gluten-free diet, and again after late challenge with gluten. In a patient with coeliac disease a flat, proximal, small intestinal mucosa heals on a gluten-free diet and relapses after challenge. However, in children, especially in those under 2 years at presentation, a flat mucosa is not pathognomonic of coeliac disease, ${ }^{2}$ and can occur in other disordersfor example, in cows' milk-sensitive enteropathy. ${ }^{3}$ A simple and reliable in vitro blood test for gluten sensitivity would help in the diagnosis of coeliac disease.

Our earlier finding 4 that antireticulin antibodies (ARA) are associated with gluten enteropathy in both coeliac disease and dermatitis herpetiformis suggested that screening for ARA by indirect immunofluorescence would provide such a test. However, ARA screening has proved of only limited value, since many untreated cases of gluten intolerance are ARA-negative. ${ }^{5}$ We describe here an immunofluorescence test for antibodies to gliadin (AGA) that is of considerably more use in the investigation of gluten sensitivity. This new test is based on the observation that gliadin binds selectively to reticulin fibres. ${ }^{6}$ On cryostat tissue sections pretreated with gliadin solution, rabbit antisera to gliadin give an immunofluorescent staining pattern almost identical with that of ARA. ${ }^{6}$ The immunofluorescent titre of such antisera correlates with antigliadin activity as measured by passive haemagglutination of gliadin-coated sheep erythrocytes. ${ }^{6}$ We have investigated the relationship of AGA demonstrated in this way in children with glutensensitive enteropathies and other gastrointestinal conditions.

\section{Patients}

We have studied a total of 290 serum samples, taken over a number of years from 192 children undergoing investigation for gastroenterological disease. A diagnosis of coeliac disease (based on the criteria laid down by ESPGAN) was confirmed in 24 children aged between 4 and 13 years; each one had 
been on a gluten-free diet for at least 2 years and had relapsed after gluten challenge. Serum samples taken at initial presentation were not available from these 24 children, but serum samples taken after gluten challenge were available from 16 of them. A provisional (unconfirmed) diagnosis of coeliac disease was made in a further 16 children aged between 8 months and 12 years (Table 3); they were taking a normal gluten-containing diet, and in each the duodenal biopsy showed a flat mucosa which responded to gluten withdrawal.

With few exceptions, the children investigated for gluten intolerance (coeliac disease or transient gluten intolerance) were aged under 2 years at initial presentation, and both groups were challenged with gluten at similar ages.

The remaining 152 children comprised 11 with presumed transient gluten intolerance aged between 2 and 14 years, ${ }^{7} 17$ with cows' milk protein-sensitive enteropathy aged between 6 and 16 months, ${ }^{3} 6$ with allergy to multiple food proteins aged between 8 months and 14 years, 21 with Crohn's disease aged between 6 and 16 years, 10 with ulcerative colitis aged between 6 and 16 years, 6 with postenteritis syndrome aged between 1 and 3 years, ${ }^{8} 20$ with toddler's diarrhoea aged between 6 and 14 months, ${ }^{9}$ 4 with intestinal parasites aged between 15 months and 7 years, 30 Gambian children with diarrhoea all of whom were under 3 years and consuming millet and rice as the major cereals, and 27 others with miscellaneous gastroenterological complaints aged between 6 months and 15 years. With the exception of the children with Crohn's disease and those with ulcerative colitis, the ages of the children without coeliac disease in this study were comparable at the time of testing with the ages of the 16 children who were presumed to have coeliac disease.

\section{Methods}

Crude wheat gliadin was prepared from Flander's wheat flour as described by Ewart, ${ }^{10}$ and freeze dried. The expected range of $\alpha, \beta, \gamma, \omega$, and gliadins, as well as a minor wheat albumin band, were shown to be present by polyacrylamide gel electrophoresis. ${ }^{11}$

ARA were detected by indirect immunofluorescence as described by Seah et al. ${ }^{4}$ Serum samples were tested at dilutions of $1 / 10$ and $1 / 40$ and were considered positive only if the characteristic $R 1$ immunofluorescent pattern ${ }^{12}$ was seen.

AGA were detected by a modification of the indirect immunofluorescence method described for ARA. $6 \mu \mathrm{m}$ cryostat sections of rat liver, kidney, and stomach were treated with an aqueous solution of wheat gliadin $(0.1 \mathrm{mg} / \mathrm{ml})$ for 30 minutes. After washing in phosphate buffered saline to remove unbound wheat protein, these gliadin-treated sections were used to screen patients' sera at dilutions of $1: 10$ and 1:40 for AGA by indirect immunofluorescence with FITC-labelled sheep antihuman immunoglobulin as the final step.

FITC-labelled sheep antihuman IgG, IgM, IgA, C3, and Ig (polyvalent) with fluorescein:protein (molar) ratios ranging between $3 \cdot 1$ and $4 \cdot 1$ were supplied by Wellcome Reagents and used at working dilutions determined by block titration.

Slides were examined with a Reichert microscope equipped with a $100 \mathrm{~W}$ quartz halogen lamp, and dark-ground condenser. The primary filter was Balzer FITC-3, the secondary Wratten 12.

\section{Results}

Serum samples taken 3 months after gluten challenge were available from 16 of the 24 children with a confirmed diagnosis of coeliac disease (Table 1). These 16 sera, as well as those from 16 untreated children with a provisional diagnosis of coeliac disease (Table 3) gave bright reticulin staining when tested by indirect immunofluorescence on gliadin pretreated cryostat sections of composite rat tissue. Only $9(28 \%)$ of these 32 children were found to have ARA when their sera were tested on cryostat sections in the conventional way, in the absence of gliadin (Tables 1 and 3). Of the 152 control children without coeliac disease whose sera were also tested, none had ARA, but $22(15 \%)$ were positive on gliadin-treated sections of rat tissue.

Table 1 shows the results of immunofluorescence tests for ARA and AGA on serum samples taken before or after gluten challenge, or at both times, from the 24 children with a confirmed diagnosis of coeliac disease. All 24 patients had been on a gluten-free diet for at least 2 years before being challenged with gluten to confirm the diagnosis. Six of the 8 patients who were tested both before and after gluten challenge were negative for AGA before challenge, but became positive within 3 months of challenge. The other 2 children were

Table 1 Results of testing sera from 24 patients with confirmed coeliac disease for AGA on gliadin-treated sections, and for $A R A$

\begin{tabular}{|c|c|c|c|c|}
\hline \multirow{2}{*}{$\begin{array}{l}\text { When tested in relation } \\
\text { to gluten challenge }\end{array}$} & \multicolumn{2}{|c|}{ Prechallenge } & \multicolumn{2}{|c|}{ Postchallenge } \\
\hline & $\begin{array}{l}A G A+ \\
(n=8)\end{array}$ & $\begin{array}{l}A R A+ \\
(n=8)\end{array}$ & $\begin{array}{l}A G A+ \\
(n=8)\end{array}$ & $\begin{array}{l}A R A+ \\
(n=8)\end{array}$ \\
\hline $\begin{array}{l}\text { Prechallenge and } \\
\text { postchallenge }(n=8) \\
\text { Prechallenge only }(n=8) \\
\text { Postchallenge only }(n=8)\end{array}$ & $\begin{array}{l}2 \\
2 \\
\text { ND }\end{array}$ & $\begin{array}{l}0 \\
1 \\
\text { ND }\end{array}$ & $\begin{array}{l}8 \\
\mathrm{ND} \\
8\end{array}$ & $\begin{array}{l}0 \\
\text { ND } \\
2\end{array}$ \\
\hline
\end{tabular}

*Taken after 2 years of a gluten-free diet and before starting gluten challenge.

ND = not done 
positive for AGA before challenge and remained positive after, but none had ARA. Another 8 children were tested before gluten challenge only. Two of them had AGA, one also having ARA. The remaining 8 children were only tested 3 months after gluten challenge. All 8 had AGA and in 2 ARA was found as well.

Thus, although all 16 children with a confirmed diagnosis of coeliac disease tested 3 months after gluten challenge were positive for AGA, only 2 had ARA. All 16 had relapsed histologically with abnormal duodenal mucosae 3 months after gluten challenge. Only 1 of the 24 children with confirmed coeliac disease had an abnormal biopsy before gluten challenge. This patient was positive for AGA but negative for ARA.

Table 2 shows the incidence of AGA in serum from 11 children presumed to have transient gluten intolerance and later confirmed according to ESPGAN criteria (normal mucosa at least 2 years after gluten challenge). AGA were detected in 1 of 5 children tested before gluten challenge, and in 6 of 10 children tested between 3 and 12 months of gluten challenge, although biopsies of all 11 showed normal mucosae both before and after gluten challenge. Table 2 also shows that all 11 children were negative for ARA both before and after challenge.

Sera from 16 untreated children with flat duodenal mucosae on investigation, who responded to a gluten-free diet and who were thus given a provisional diagnosis of coeliac disease, all had AGA, although only 6 had ARA. Five children were retested after 3 months on a gluten-free diet and all 5 remained positive for AGA. Table 3 contrasts results on these 16 children with provisionally diagnosed coeliac disease, with those on 20 noncoeliac children who also had abnormal mucosae ranging from partial villous atrophy to flat. Only 3 of the children with flat mucosae were positive for

Table 2 Results of tests on sera from 11 patients in whom coeliac disease was originally diagnosed but in whom results were histologically negative on challenge (presumed to have had transient gluten intolerance)

\begin{tabular}{|c|c|c|c|c|}
\hline \multirow{2}{*}{$\begin{array}{l}\text { When tested in relation } \\
\text { to gluten challenge }\end{array}$} & \multicolumn{2}{|c|}{ Prechallenge* } & \multicolumn{2}{|c|}{ Postchallenge $\dagger$} \\
\hline & $\begin{array}{l}A G A+ \\
(n=5)\end{array}$ & $\begin{array}{l}A R A+ \\
(n=5)\end{array}$ & $\begin{array}{l}A G A+ \\
(n=10)\end{array}$ & $\begin{array}{l}A R A+ \\
(n=10)\end{array}$ \\
\hline $\begin{array}{l}\text { Prechallenge and } \\
\text { postchallenge }(n=4)\end{array}$ & 1 & $\mathbf{0}$ & 3 & $\mathbf{0}$ \\
\hline Postchallenge only $(n=6)$ & ND & ND & 3 & $\mathbf{0}$ \\
\hline Prechallenge only $(n=1)$ & 0 & 0 & ND & ND \\
\hline
\end{tabular}

*Taken after 2 years on a gluten-free diet and before starting gluten challenge.

†Taken between 3 and 24 months after gluten challenge.

ND $=$ not done.
AGA, and none of them had ARA. Two of the 3 children positive for AGA had cows' milk proteinsensitive enteropathy, and the third, presumed to have transient gluten intolerance, may yet prove to have coeliac disease.

Table 4 shows the incidence of AGA in the 152 patients without coeliac disease. None of these patients was positive for ARA, but $22(15 \%)$ were positive for AGA. The majority (17) of these AGApositive control patients belonged to either the

Table 3 Results of $A G A$ and ARA in children with abnormal, small intestinal mucosae tested at initial investigation

\begin{tabular}{llll}
\hline $\begin{array}{l}\text { Untreated children }(n=16) \\
\text { disease }\end{array}$ & with a provisional diagnosis of coeliac \\
\hline Age at testing & Biopsy & $\begin{array}{l}\text { AGA } \\
(n=16)\end{array}$ & $\begin{array}{l}\text { ARA } \\
(n=16)\end{array}$ \\
\hline 11 months & Flat & ++ & - \\
18 months & Flat & +++ & + \\
12 years & Flat & ++ & ++ \\
9 months & Flat & ++ & - \\
12 years & Flat & ++ & - \\
$2 \frac{1}{2}$ years & Flat & +++ & Weak \\
8 months & Flat & ++ & - \\
10 months & Flat & ++ & - \\
15 months & Flat & + & + \\
10 years & Flat & +++ & - \\
9 months & Flat & ++ & - \\
26 months & Flat & ++ & + \\
12 years & Flat & + & - \\
1 year & Flat & ++ & - \\
9 months & Flat & ++ & - \\
9 years & Flat & +++ & ++ \\
\hline
\end{tabular}

Children $(n=20)$ without coeliac disease

\begin{tabular}{|c|c|c|c|c|}
\hline Diagnosis & $\begin{array}{l}\text { Age at } \\
\text { testing }\end{array}$ & Biopsy* & $\begin{array}{l}A G A \\
(n=20)\end{array}$ & $\begin{array}{l}A R A \\
(n=20)\end{array}$ \\
\hline \multicolumn{5}{|l|}{ Transient gluten } \\
\hline \multicolumn{5}{|l|}{ Transient gluten } \\
\hline intolerance & 9 months & + & - & - \\
\hline CMSE & 15 months & $+1++$ & - & - \\
\hline CMSE & 6 months & ++ & + & - \\
\hline CMSE & 1 year & Flat & - & - \\
\hline CMSE & 10 months & ++ & $+t$ & - \\
\hline CMSE & 14 months & + & - & - \\
\hline CMSE & 5 months & $++1+++$ & - & - \\
\hline CMSE & 6 months & Flat & - & - \\
\hline CMSE & 9 months & ++ & - & - \\
\hline \multicolumn{5}{|l|}{ Mixed food } \\
\hline protein intolerance & 16 months & + & - & - \\
\hline Giardiasis & 6 years & Flat & - & - \\
\hline Giardiasis & 7 years & $++1+$ & - & - \\
\hline Giardiasis & 15 months & $+1++$ & - & - \\
\hline Trichomonas & 13 months & Flat & - & - \\
\hline \multicolumn{5}{|l|}{ Postenteritis } \\
\hline syndrome & 33 months & + & - & - \\
\hline \multicolumn{5}{|l|}{ Postenteritis } \\
\hline syndrome & 17 months & $+1++$ & - & - \\
\hline \multicolumn{5}{|l|}{ Postenteritis } \\
\hline \multirow{2}{*}{\multicolumn{5}{|c|}{$\begin{array}{l}\text { Diarrhoea } \\
\text { Hirschprung's }\end{array}$}} \\
\hline & & & & \\
\hline syndrome & $4 \frac{1}{2}$ years & $+1++$ & - & - \\
\hline
\end{tabular}

* Recorded as + for mild villous atrophy, ++ severe villous atrophy. $\square$ CMSE = cows' milk protein-sensitive enteropathy. 
Table 4 Incidence of $A G A$ in 152 children without coeliac disease

\begin{tabular}{lll}
\hline Group & \multicolumn{2}{l}{ Children with AGA } \\
\cline { 2 - 3 } & No & $\%$ \\
\hline Transient gluten intolerance $(\mathrm{n}=11)$ & 6 & 55 \\
$\begin{array}{l}\text { Cows' milk protein-sensitive } \\
\text { enteropathy }(\mathrm{n}=17)\end{array}$ & 4 & 24 \\
Multiple food allergy $(\mathrm{n}=6)$ & 1 & 16 \\
Crohn's disease $(\mathrm{n}=21)$ & 7 & 33 \\
Ulcerative colitis $(\mathrm{n}=10)$ & 1 & 10 \\
Postenteritis syndrome $(\mathrm{n}=16)$ & 0 & - \\
Toddler's diarrhoea $(\mathrm{n}=20)$ & 2 & 10 \\
Intestinal parasites $(\mathrm{n}=4)$ & 0 & - \\
Gambian children $(\mathrm{n}=30)$ & 1 & 3 \\
Other complaints $(\mathrm{n}=27)$ & 0 & - \\
\hline
\end{tabular}

group of children with Crohn's disease $(n=7)$, or had clinical and biopsy evidence of the food protein intolerance syndrome of infancy (to gluten $n=6$, and to cows' milk protein $n=4$ ). In the group with Crohn's disease, although the incidence of AGA did not appear to correlate with disease activity, all 7 patients with Crohn's disease and AGA had smallbowel involvement. However, 9 of the 14 AGAnegative patients with Crohn's disease also had small-bowel involvement. The lesion in the other 5 AGA-negative patients with Crohn's disease was confined to the colon.

Small intestinal biopsies were not taken from the patients with Crohn's disease or from those with ulcerative colitis, nor were they taken from the Gambian children, but biopsy data were available from 13 of the 22 AGA-positive control children (Table 4). As stated above, only 3 of them had abnormal mucosae (Table 3).

Although not all of the AGA-positive sera were tested with class specific FITC conjugated antihuman immunoglobulin, in cases where this was done (20 sera) the antibodies were of the IgG class, and in some individuals IgA was also found. IgM AGA was not found in any of the sera tested.

\section{Discussion}

Our observation ${ }^{6}$ that gliadin binds to reticulin fibres in cryostat sections led to the development of this method of detecting gliadin antibodies.

All the 32 children with a provisional or confirmed diagnosis of coeliac disease we have so far studied gave the reticulin pattern of staining when their sera were tested on gliadin-treated sections of rat tissue. The sera from the majority $(85 \%)$ of the 152 noncoeliac children tested did not give reticulin staining when tested in this manner. The test appears specifically to detect gluten sensitivity rather than coeliac disease, since positives were also seen in transient gluten intolerance, cows' milk proteinsensitive enteropathy, and Crohn's disease, and occasionally in other groups (Table 4). It therefore appears likely to be especially useful as a simple screening test, a negative result excluding at initial investigation a diagnosis of coeliac disease (Table 3 ). The test is of less value in confirming a diagnosis of coeliac disease, which must still rely on biopsy evidence before and after late challenge. Further work may establish the value of the test for monitoring diet in established coeliac disease and in determining when to biopsy after gluten challenge.

After late gluten challenge, AGA was found in some children with presumed transient gluten intolerance, even though small intestinal biopsy showed a normal mucosa after 2 years of gluten challenge. However, the diagnosis of transient gluten intolerance remains controversial since in an occasional, atypical coeliac child relapse may take longer than 2 years ${ }^{13}$ and McNeish et al. ${ }^{14}$ now advocate more rigorous criteria than those of the ESPGAN for the diagnosis of transient gluten intolerance. This is a puzzling observation and it remains to be seen whether or not those AGApositive children who have been diagnosed as having transient gluten intolerance will remain gluten tolerant or whether they will ultimately relapse.

In Crohn's disease we found positive AGA tests in 7 of 16 patients with small-intestinal involvement, but in none with disease confined to the large intestine. This may suggest that the presence of serum AGA reflects increased permeability to food antigen, although we did find AGA in some children in this study who had normal small-intestinal mucosae.

We have shown that purified $\alpha$-gliadin binds to reticulin in vitro, ${ }^{6}$ but cannot rule out the possibility that other gliadins, and perhaps the wheat albumin present in the crude gliadin preparation used in this study, also bind. This needs further study.

Finally, the binding of gliadin to reticulin fibres in vivo would provide a local focus for complement activation in association with specific, or crossreacting ${ }^{5}$ antibody. Bound gliadin per se would also activate complement via the alternative pathway, ${ }^{15}$ and it is possible that tissue damage resulting from complement activation renders reticulin immunogenic. The finding of Shiner and Ballard ${ }^{16}$ that the earliest postchallenge jejunal lesion in coeliac disease involves connective tissue fibres in the lamina propria would support our hypothesis that the binding of gliadin to reticulin fibres which we report here may have pathogenetic significance.

We thank Dr M G M Rowland, MRC Dunn Nutritional Unit, Milton Road, Cambridge, for 
permission to quote the results of investigations on sera from Gambian children.

\section{J U was supported by the Children's Research} Fund, Liverpool.

\section{References}

1 Anonymous. Confirming the diagnosis of coeliac disease. Br Med J 1975; iv: 2.

2 Visakorpi J K. Definition of coeliac disease in children. In: Hekkens W Th J M, Penä A S, eds. Coeliac disease. Proceedings of the Second International Coeliac Symposium, Leiden 1974. Leiden: Stenfert Kroese, 1974: 10-6.

3 Walker-Smith J, Harrison M, Kilby A, Phillips A, France N. Cows' milk sensitive enteropathy. Arch Dis Child 1978; 53: 375-80.

4 Seah P P, Fry L, Hoffbrand A V, Holborow E J. Tissue autoantibodies in dermatitis herpetiformis and adult coeliac disease. Lancet 1971 ; i: 834-6.

5 Seah P P, Fry L, Holborow E J, et al. Antireticulin antibody: incidence and diagnostic significance. Gut 1973; 14: 311-5.

6 Unsworth D J, Johnson G D, Haffenden G, Fry L, Holborow $\mathrm{E} J$. Binding of wheat gliadin in vitro to reticulin in normal and dermatitis herpetiformis skin. J Invest Dermatol 1981; 76: 88-93.

7 Walker-Smith J A. Transient gluten intolerance. Arch Dis Child 1970; 45: 523-6.

8 Walker-Smith J A. Post enteritis syndrome. In: WalkerSmith J A, ed. Diseases of the small intestine in childhood, second edition. Tunbridge Wells: Pitman Medical, 1979: 241-9.
9 Burke V, Anderson C. The irritable colon syndrome. In: Anderson C M, Burke V, eds. Paediatric gastroenterology. Oxford: Blackwell, 1975: 469-71.

10 Ewart J A D. Isolation of a Capelle Desprez gliadin. J Sci Food Agric 1975; 26: 1021-5.

11 Bushuk W, Zillman R A. Wheat cultivar identification by gliadin electrophoretograms. Can J Plant Sci 1977; 58: 505-15.

12 Rizzetto M, Doniach D. Types of 'reticulin antibodies' detected in human sera by immunofluorescence. $J$ Clin Pathol 1973; 26: 841-51.

13 McNeish A S, Harms H K, Rey J, Shmerling D H, Visakorpi J K, Walker-Smith $\mathbf{J}$ A. The diagnosis of coeliac disease. Commentary on the current practices of members of the European Society for Paediatric Gastroenterology and Nutrition (ESPGAN). Arch Dis Child $1979 ; 54: 783-6$.

14 McNeish A S, Rolles C J, Arthur L J H. Criteria for diagnosis of temporary gluten intolerance. Arch Dis Child 1976; 51 : 275-8.

15 Massey A, Capner P M, Mowbray J F. Activation of the alternative pathway by gluten. Immunology 1977; 33: 339-42.

16 Shiner $M$, Ballard J. Antigen-antibody reactions in jejunal mucosa in childhood coeliac disease after gluten challenge. Lancet 1972; i: 1202-5.

Correspondence to Professor E J Holborow, London Hospital Medical College, Bone and Joint Research Unit, 25-29 Ashfield Street, London E1 2AD.

Received 10 September 1980 